\title{
Influence of proton-irradiation temperature on the damage accumulation in Ti3SiC2 and Ti3AIC2
}

DOI:

10.1016/j.scriptamat.2019.02.022

\section{Document Version}

Accepted author manuscript

Link to publication record in Manchester Research Explorer

\section{Citation for published version (APA):}

Ward, J., Bowden, D., Stewart, D., Barsoum, M. W., Frankel, P., \& Preuss, M. (2019). Influence of proton-

irradiation temperature on the damage accumulation in $\mathrm{Ti}_{3} \mathrm{SiC}_{2}$ and $\mathrm{Ti}_{3} \mathrm{AlC}_{2}$. Scripta Materialia.
https://doi.org/10.1016/j.scriptamat.2019.02.022

\section{Published in:}

Scripta Materialia

\section{Citing this paper}

Please note that where the full-text provided on Manchester Research Explorer is the Author Accepted Manuscript or Proof version this may differ from the final Published version. If citing, it is advised that you check and use the publisher's definitive version.

\section{General rights}

Copyright and moral rights for the publications made accessible in the Research Explorer are retained by the authors and/or other copyright owners and it is a condition of accessing publications that users recognise and abide by the legal requirements associated with these rights.

\section{Takedown policy}

If you believe that this document breaches copyright please refer to the University of Manchester's Takedown Procedures [http://man.ac.uk/04Y6Bo] or contact uml.scholarlycommunications@manchester.ac.uk providing relevant details, so we can investigate your claim.

\section{OPEN ACCESS}




\section{Influence of proton-irradiation temperature on the damage accumulation in $\mathrm{Ti}_{3} \mathrm{SiC}_{2}$ and $\mathrm{Ti}_{3} \mathrm{AlC}_{2}$}

Joseph Ward ${ }^{1,2}$, David Bowden ${ }^{1 *}$, David Stewart ${ }^{2}$, Michel W. Barsoum ${ }^{3}$, Philipp Frankel ${ }^{1}$, Michael Preuss ${ }^{1}$.

${ }^{1}$ School of Materials, The University of Manchester, Manchester, UK; davidjamesbowden@gmail.com, philipp.frankel@manchester.ac.uk, michael.preuss@manchester.ac.uk

${ }^{2}$ Rolls-Royce plc., Derby, UK; joseph.ward@rolls-royce.com, david.stewart1@rollsroyce.com

${ }^{3}$ Department of Materials Science and Engineering, Drexel University, Philadelphia, USA; barsoumw@drexel.edu

*Corresponding author: D. Bowden, davidjamesbowden@gmail.com

The effect of irradiation temperature on the crystallographic stability of the ternary carbides $\mathrm{Ti}_{3} \mathrm{SiC}_{2}$ and $\mathrm{Ti}_{3} \mathrm{AlC}_{2}$ was investigated in the 350 to $600{ }^{\circ} \mathrm{C}$ temperature range, using $2 \mathrm{MeV}$ protons to a fluence of $2.25 \times 10^{18}$ protons $\mathrm{cm}^{-2}$. Both materials shrink along the basal planes and expand normal to them. Defect recovery decreases the magnitude of these anisotropic lattice changes with increasing irradiation temperature. However, reduced recovery in $\mathrm{Ti}_{3} \mathrm{AlC}_{2}$ causes irradiated surface exfoliation at low temperatures and elevated damage rates. The extent of lattice change suggests that in-reactor use of these compositions will likely be limited to high-temperature applications.

Keywords: Proton irradiation, annealing, X-ray diffraction (XRD), layered structures, point defects.

The MAX phases are a group of ternary carbides and nitrides, where $M$ denotes an early transition metal, $\mathrm{A}$ is an A-group element and $\mathrm{X}$ is either carbon or nitrogen. Their nano-layered hexagonal crystal structure consists of single atomic metallic A-layers sandwiched between MX carbide layers. The metallic and ceramic layers give MAX phases a unique mix of properties such as ease of machinability [1], whilst being thermally shock resistant and damage tolerant [2]. Due to this combination of properties, MAX phases have been suggested as suitable materials for nuclear applications, such as accident tolerant fuel coatings (ATFCs) for light water reactors (LWR) [3], as well as for various Gen IV applications [4]. Such 
applications require chemical and structural stability at the expected operating temperatures and resistance to irradiation damage.

Previous studies have observed anisotropic lattice changes in $\mathrm{Ti}_{3} \mathrm{AlC}_{2}$ and $\mathrm{Ti}_{3} \mathrm{SiC}_{2}$ after heavy ion irradiation, whereby an increase in c-lattice parameter alongside a decrease in alattice parameter occurs [5-9]. At temperatures below $400{ }^{\circ} \mathrm{C}$, the anisotropic lattice changes lead to grain boundary cracking [5]. However, at temperatures above $400{ }^{\circ} \mathrm{C}$, the irradiationinduced lattice parameter changes during heavy ion irradiation were less severe in these MAX phases than the lower temperature counterparts [5,7-9]. Neutron irradiation has shown similar trends of reduced lattice changes at temperatures of $695^{\circ} \mathrm{C}$ and greater $[8,10]$. Therefore, it has previously been concluded that $\mathrm{Ti}_{3} \mathrm{AlC}_{2}$ and $\mathrm{Ti}_{3} \mathrm{SiC}_{2}$ will be limited to use in environments where operating temperatures are greater than $400{ }^{\circ} \mathrm{C}[5,7-12]$.

It has been proposed that point defect and point defect cluster accumulation is responsible for the lattice parameter changes in these materials, specifically $M_{A}$ and $A_{M}$ antisite defects and $\mathrm{C}_{\mathrm{i}}$ Frenkel defects $[5,13]$. The use of higher irradiation temperatures is expected to increase the migration and annihilation of point defects, thus reducing lattice strains by reducing residual point defects. A direct comparison of the proton irradiation response of these materials at varying temperatures has not been carried out previously.

Therefore, the following work is a systematic study of the effect of irradiation temperature on defect accumulation in $\mathrm{Ti}_{3} \mathrm{SiC}_{2}$ and $\mathrm{Ti}_{3} \mathrm{AlC}_{2}$. Response of the lattice to irradiation temperature variation is investigated. Ex-situ XRD is used to investigate the irradiation stability of the material by measuring irradiation-induced changes in the lattice parameter. By carefully controlling the irradiation conditions, this study aims to provide a sound basis to improve understanding of the mechanisms that determine the evolution of damage in MAX phase materials at mid-range irradiation temperatures $\left(350-600{ }^{\circ} \mathrm{C}\right)$, providing essential validation for proposed models of defect evolution. The temperature range covered here replicates typical LWR conditions as well as the higher temperatures expected in many Gen IV applications.

$\mathrm{Ti}_{3} \mathrm{SiC}_{2}$ and $\mathrm{Ti}_{3} \mathrm{AlC}_{2}$ bulk samples (minimum of $98 \%$ MAX phase purity, remainder is TiC) were synthesised from hot pressing powders under $30-40 \mathrm{MPa}$ at $1300-1500{ }^{\circ} \mathrm{C}$ as described in [11,14]. Samples were electrical discharge machined (EDM) into $2 \times 4 \times 20 \mathrm{~mm}^{3}$ bars that were subsequently ground and polished to a mirror finish using an oxide polishing suspension (OPS).

Proton $\left(\mathrm{H}^{+}\right)$irradiation was carried out at the Dalton Cumbrian Facility (DCF) at the University of Manchester [15], on a $4 \times 10 \mathrm{~mm}^{2}$ region of each bar using $2 \mathrm{MeV} \mathrm{H}^{+}$with a 
current density of $0.2 \mu \mathrm{A} \mathrm{mm} \mathrm{mm}^{-2}$. Irradiations were carried out at $50{ }^{\circ} \mathrm{C}$ intervals between 350 and $600{ }^{\circ} \mathrm{C}$ (maximum possible temperature for this furnace), with a maximum temperature variation of $\pm 10^{\circ} \mathrm{C}$. Dose profiles, calculated using quick Kinchin-Pease calculation in SRIM [16] for a million ion collisions, are shown in Fig. 1a. Standard values of displacement threshold were used in SRIM for Ti, $\mathrm{Al}$ and $\mathrm{C}$ of $25 \mathrm{eV}, 25 \mathrm{eV}$ and $28 \mathrm{eV}$, respectively and result in a Bragg peak of maximum damage for both samples at around $28 \mu \mathrm{m}$. The damage rate was calculated as $5.4 \times 10^{-6} \mathrm{dpa} \mathrm{s}^{-1}$ at a depth of $\sim 17 \mu \mathrm{m}$, i.e. $60 \%$ of the maximum damage, a typical depth where XRD data is collected. At this depth, a dose of $0.1 \mathrm{dpa}\left(2.25 \times 10^{18} \mathrm{H}^{+}\right.$ $\mathrm{cm}^{-2}$ total dose, measured across the irradiated area at the sample surface) was reached during the experiment.

Ex-situ XRD on the irradiated samples was performed on a Bruker D8 Discover diffractometer with a $\mathrm{Cu} \mathrm{K} \mathrm{K}_{\alpha}$ source. All irradiated materials were analysed at room temperature. Scans were performed with a $0.4 \mathrm{~mm}$ vertical slit and $2 \mathrm{~mm}$ horizontal slit, thus ensuring that only the irradiated region was sampled. A two-theta range of $30^{\circ}$ to $80^{\circ}$ was collected using a step size of $0.02^{\circ}$, counting for $3 \mathrm{~s}$ per step. Calculation of the cumulative $\mathrm{X}$ ray signal generated across the entire two-theta range, reveals that the depth from which XRD signal is measured does not exceed $19 \mu \mathrm{m}$ in $\mathrm{Ti}_{3} \mathrm{AlC}_{2}$ (Fig. 1b). For $\mathrm{Ti}_{3} \mathrm{SiC}_{2}$ the XRD signal depth is $18 \mu \mathrm{m}$. Therefore, the Bragg peak of $\mathrm{H}^{+}$damage is not sampled during XRD analysis. Experimental lattice parameters were obtained through Rietveld refinement of collected diffraction patterns in TOPAS v4 [17]. Measured lattice parameters in the as-received condition were: $3.07 \AA$ and $18.56 \AA$ for the a and c-parameter, respectively, in $\mathrm{Ti}_{3} \mathrm{AlC}_{2}$. For $\mathrm{Ti}_{3} \mathrm{SiC}_{2}$, the measured as-received a and c-parameters were $3.07 \AA$ and $17.67 \AA$ respectively.

XRD diffraction patterns obtained after irradiation are shown in Fig. 2a and b, where the effect of irradiation temperature on lattice parameters is apparent. The basal reflection (0008) was observed to shift to lower $2 \theta$ values (increase in d-spacing) with lower irradiation temperatures. Peak broadening occurs after irradiation, leading to an overlapping of $\mathrm{K}_{\alpha 1}$ and $\mathrm{K}_{\alpha 2}$ for each peak, which is observed more readily at lower irradiation temperatures. It is noted that since the XRD signal is generated through a material thickness where irradiation dose is not constant (Fig. 1b), the lattice parameters may vary with depth, possibly contributing to the observed broadening effect. The lattice parameter strains, relative to non-irradiated samples at room temperature, are calculated from the diffraction patterns and are shown in Fig. $2 \mathrm{c}$ and $\mathrm{d}$ for $\mathrm{Ti}_{3} \mathrm{SiC}_{2}$ and $\mathrm{Ti}_{3} \mathrm{AlC}_{2}$, respectively. In both materials studied, the c-parameter increases after $\mathrm{H}^{+}$irradiation while the a-parameter reduces, in agreement with previous observations for 
neutron and heavy ion irradiated materials. [5-9]. Additionally, a linear trend is observed in lattice parameter change with irradiation temperature, where overall lattice strain is reduced with increasing irradiation temperature.
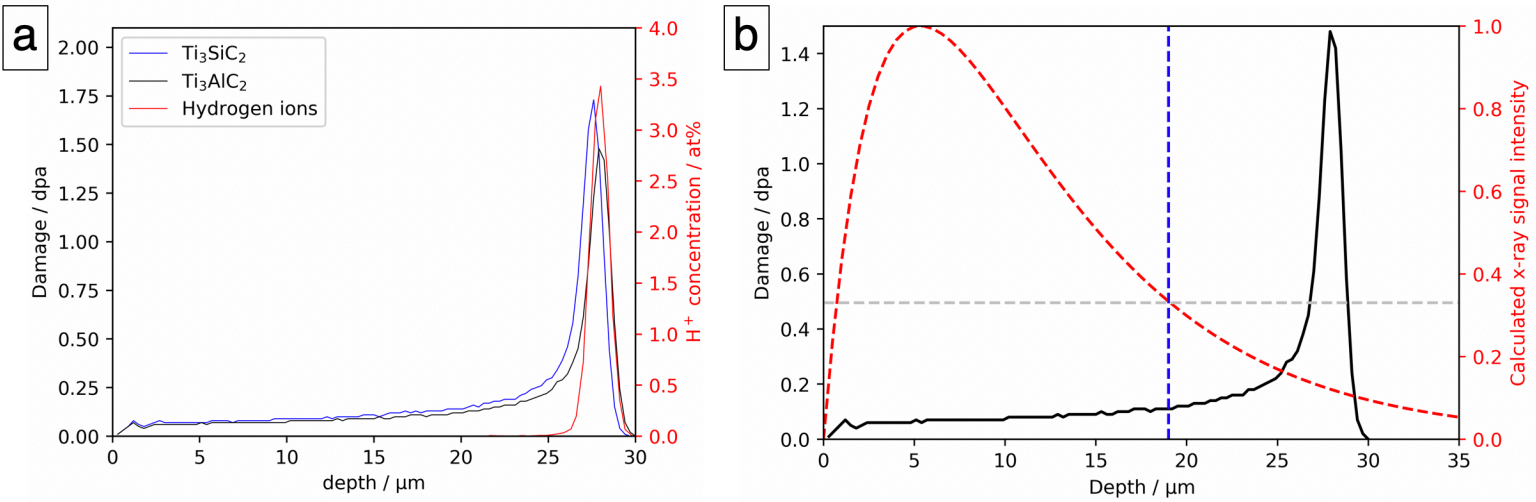

Figure 1: Simulated $\mathrm{H}^{+}$damage profiles and $\mathrm{XRD}$ penetration calculations. (a) $\mathrm{H}+$ damage profiles for $\mathrm{Ti}_{3} \mathrm{SiC}_{2}$ (blue) and $\mathrm{Ti}_{3} \mathrm{AlC}_{2}$ (black), using $2 \mathrm{MeV}$ protons with an area current of $0.2 \mu \mathrm{A} \mathrm{mm}{ }^{-2}$, calculated using SRIM. Relative concentration of $\mathrm{H}+$ ions in $\mathrm{Ti}_{3} \mathrm{AlC}_{2}$ shown in red. (b) XRD signal intensity calculation for $\mathrm{Ti}_{3} \mathrm{AlC}_{2}$. The red dashed line shows the normalised XRD signal intensity as a function of depth compared to the $\mathrm{H}+$ damage profile (black line). Below 33\% X-ray signal intensity (grey dashed line), the signal is obscured by noise and therefore X-ray penetration beyond this depth (blue dashed line), will not contribute to the collected XRD data. For $\mathrm{Ti}_{3} \mathrm{AlC}_{2}$, the maximum XRD signal depth is approximately $19 \mu \mathrm{m}$ sub-surface and for $\mathrm{Ti}_{3} \mathrm{SiC}_{2}$ it is $18 \mu \mathrm{m}$ (not shown).

Comparing Figs. 2c and d, it is clear that at all irradiation temperatures, the lattice strains are higher for $\mathrm{Ti}_{3} \mathrm{AlC}_{2}$ than $\mathrm{Ti}_{3} \mathrm{SiC}_{2}$, in agreement with previous observations from heavy ion and neutron irradiation experiments $[5,12]$. The amount of recovery exhibited by $\mathrm{Ti}_{3} \mathrm{AlC}_{2}$ is also reduced at increased temperatures when compared with $\mathrm{Ti}_{3} \mathrm{SiC}_{2}$. The gradients of the linear fits of the c-lattice parameter data points are $-0.003 \%{ }^{\circ} \mathrm{C}^{-1}$ and $-0.0017 \%{ }^{\circ} \mathrm{C}^{-1}$ for $\mathrm{Ti}_{3} \mathrm{SiC}_{2}$ and $\mathrm{Ti}_{3} \mathrm{AlC}_{2}$, respectively. A greater density of residual defects in $\mathrm{Ti}_{3} \mathrm{AlC}_{2}$, which are postulated to cause the lattice strain, have been predicted by DFT in previous proton irradiation work [13]. It is proposed that the lower formation energy of defects produced in $\mathrm{Ti}_{3} \mathrm{AlC}_{2}$, specifically $\mathrm{C}$ interstitials and $\mathrm{M}_{\mathrm{A}}$ antisites, results in a higher defect population after irradiation. The reduction in peak resolution in the (0008) reflection could indicate that defects populate the basal planes, which supports the theory presented previously [13].

While no dislocation loops were observed to have formed in the proton irradiated sample previously at $0.1 \mathrm{dpa}$, similar peak broadening was observed [13]. In the absence of loops, or other visible defects such as ripplocations $[10,18,19]$, it is likely that defects are present in the form of nanoscale interstitial defect clusters and point defects, which are believed 
to cause the lattice distortion $[5,13]$. Typical point defects are not expected to cause the type of peak broadening observed here [20] since their strain field is limited (i.e. inversely proportional to $r^{3}$, where $r$ is the distance from the defect [21]). The MAX phases, however, have a unique nanolayered structure, where point defects can accumulate between the A and M-layers. It is believed that this layered structure results in a non-uniform strain field around point defects and therefore contributes to both peak shift and broadening. Although, as discussed earlier, it is also possible that lattice parameter variation across the irradiated profile sampled during XRD analysis (Fig. 1b) could contribute to this broadening effect.
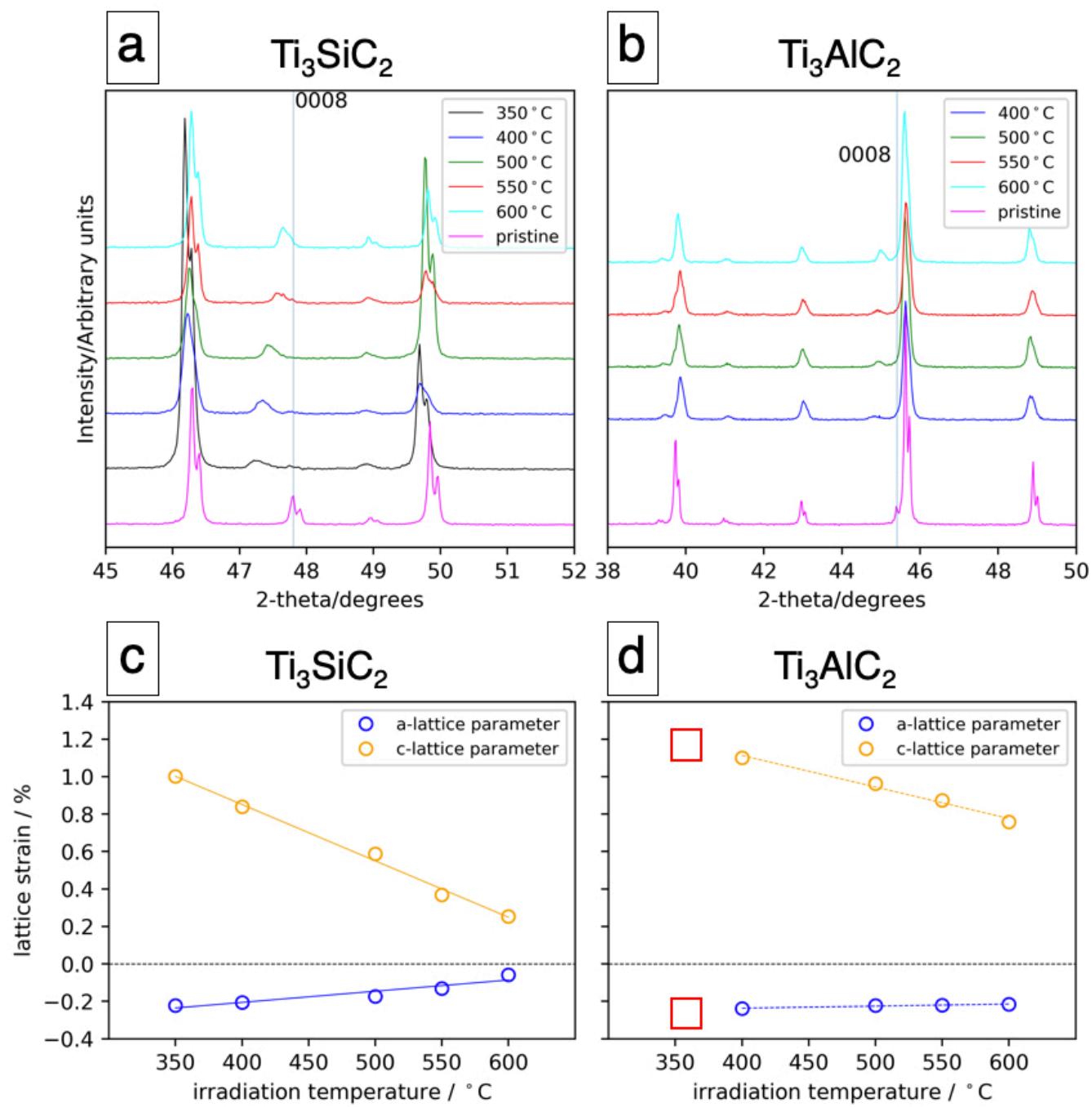

Figure 2: Analysis of post-irradiated lattice strains at various temperatures using XRD. Patterns of (a) $\mathrm{Ti}_{3} \mathrm{SiC}_{2}$ and (b) $\mathrm{Ti}_{3} \mathrm{AlC}_{2}$ after irradiation to 0.1 dpa at different irradiation temperatures. Lattice parameter strains relative to the non-irradiated samples for (c) $\mathrm{Ti}_{3} \mathrm{SiC}_{2}$ and $(\mathrm{d}) \mathrm{Ti}_{3} \mathrm{AlC}_{2}$ calculated from the diffraction patterns at different temperatures. The dotted line at $0 \%$ strain is the non-irradiated reference. Red-boxed regions in (d) are missing data points due to sample failure during testing. 
XRD results from the $\mathrm{Ti}_{3} \mathrm{AlC}_{2}$ sample, irradiated at $350{ }^{\circ} \mathrm{C}$, are not present in Fig. $2 \mathrm{~b}$ or $\mathrm{d}$ as the irradiated region of this sample did not survive the $\mathrm{H}^{+}$irradiation. An optical image of the damaged sample is shown in Fig. 3a where the irradiated region of the sample had exfoliated and detached during proton irradiation. A Keyence VK-X200K scanning laser confocal microscope was used to produce a height map of the interface between the irradiated and non-irradiated regions on the exfoliated $\mathrm{Ti}_{3} \mathrm{AlC}_{2}$ sample, shown in Fig. $3 \mathrm{~b}$. The height map shows that sample failure occurred at a depth of $\sim 30 \mu \mathrm{m}$ below the irradiated surface. This depth correlates with the maximum $\mathrm{H}^{+}$damage depth (Bragg peak) of $28 \mu \mathrm{m}$ calculated from the SRIM damage profile, shown in Fig. 3c. The sample exfoliated after an accumulated dose of $0.73 \mathrm{dpa}$ at the Bragg peak, with a corresponding damage rate of $1.8 \times 10^{-4} \mathrm{dpa} \mathrm{s}^{-1}$.

Interestingly, $\mathrm{Ti}_{3} \mathrm{AlC}_{2}$ was previously found to remain stable, with no exfoliation, during proton irradiation at $350{ }^{\circ} \mathrm{C}$ despite reaching a maximum damage of $1.5 \mathrm{dpa}$ [13]. The difference between the two proton irradiation setups was the peak damage rate. In previous work it was $4.5 \times 10^{-5} \mathrm{dpa} \mathrm{s}^{-1}[13]$; herein it is $1.8 \times 10^{-4} \mathrm{dpa} \mathrm{s}^{-1}$. These results suggest that both damage rate and irradiation temperature are important interrelated parameters affecting MAX phase stability. It should be noted that heavy ion irradiations have been performed on $\mathrm{Ti}_{3} \mathrm{AlC}_{2}$ at significantly higher dose rates and to higher doses with no reported exfoliation, even at room temperature $[9,22]$. This discrepancy may relate to differences in the defect type produced in each case, but also to the small penetration depths reached in most heavy ion experiments, where less constraint is provided by the surrounding material.

Whilst the accumulation of defects may lead to exfoliation, another possibility is that H-bubble formation could lead to sub-surface delamination as observed in other metals and ceramics undergoing ion-irradiation [23-25]. The SRIM profile shown in Fig. 1a demonstrates how $\mathrm{H}$ ions accumulate at the Bragg peak of irradiation damage. The proton fluence of $2.2 \mathrm{H}^{+}$ $\mathrm{cm}^{-2}$, used in this study, equates to a total $\mathrm{H}$ concentration of approximately $13 \mathrm{at} \%$ integrated across the Bragg peak in both $\mathrm{Ti}_{3} \mathrm{AlC}_{2}$ and $\mathrm{Ti}_{3} \mathrm{SiC}_{2}$ (Fig. 1a). In Al, hydrogen saturation occurs at a concentration of $5 \mathrm{at} \%$, leading to rapid bubble precipitation [26]. Previous research of $\mathrm{H}+$ irradiation of $\mathrm{Si}$ [27] suggests that $\mathrm{Si}$ reaches $\mathrm{H}$ saturation at approximately $10 \mathrm{at} \%$. The reduced solubility of $\mathrm{H}$ in $\mathrm{Al}$ versus Si may explain why the $\mathrm{Ti}_{3} \mathrm{AlC}_{2}$ sample exfoliated whilst $\mathrm{Ti}_{3} \mathrm{SiC}_{2}$ did not. This would possibly suggest that the A-layers, particularly in MAX phases containing $\mathrm{Al}$, are susceptible to $\mathrm{H}$ bubble formation during irradiation. However, the absence of such blistering at greater damages previously [13] suggests that damage rate is still an 
important factor. This could be due to the competition between $\mathrm{H}$-implantation versus $\mathrm{H}$ diffusion away from the Bragg peak.

Finally, scanning electron microscope (SEM) micrographs of the exfoliated $\mathrm{Ti}_{3} \mathrm{AlC}_{2}$ sample, collected on a Quanta 250 field emission gun (FEG) SEM, operating at $20 \mathrm{KeV}$, are shown in Figs. 3d and e. The non-irradiated surface is as-polished, showing only small pores and $\mathrm{TiC}$ grains (black and white arrows on Fig. 3d, respectively). It is interesting to note, that after irradiation, the underlying layered structure has been revealed within the damaged region (inset in Fig. 3e).
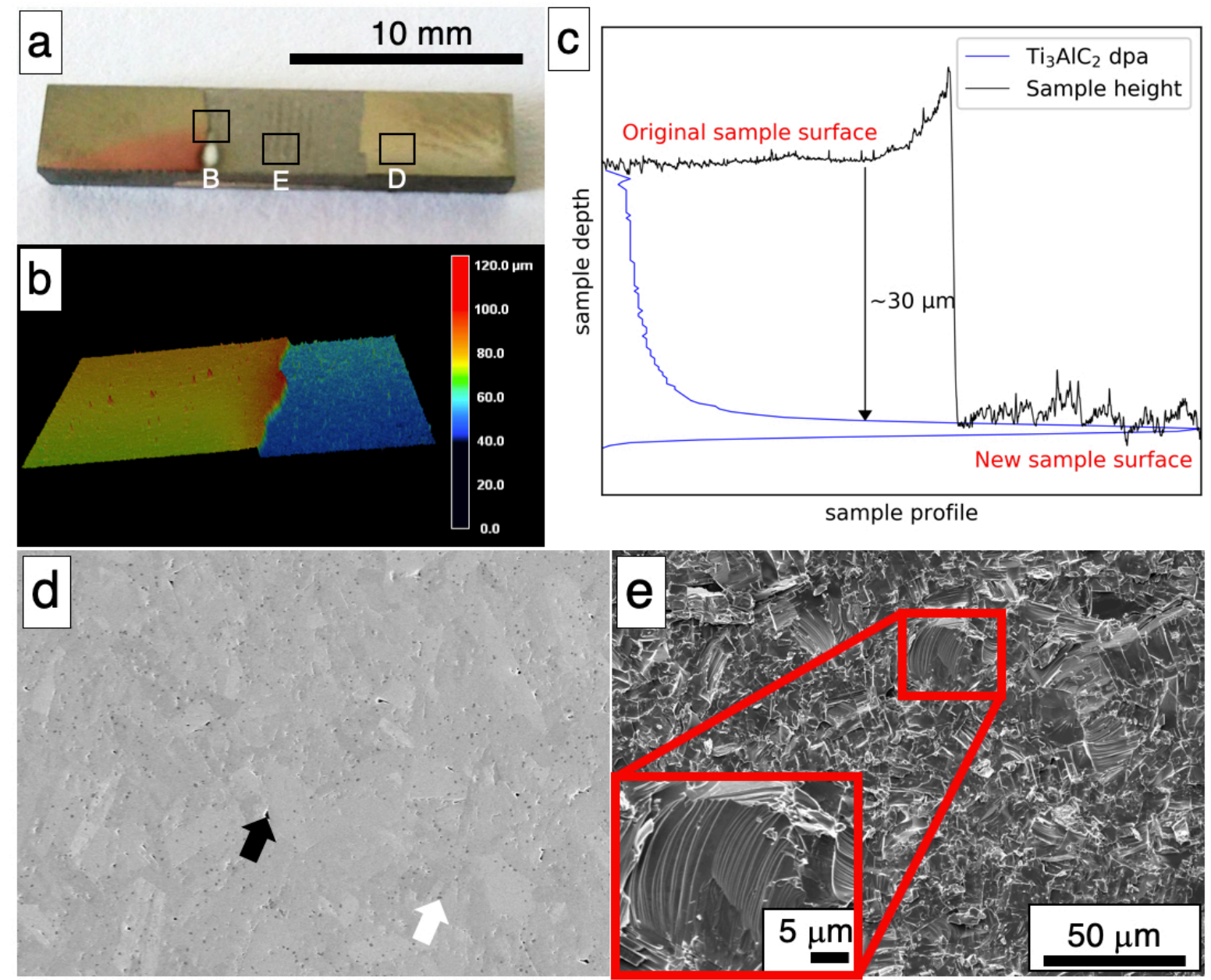

Figure 3: Examination of the exfoliated surface of the post-irradiated $\mathrm{Ti}_{3} \mathrm{AlC}_{2}$. a) Optical image of $\mathrm{Ti}_{3} \mathrm{AlC}_{2}$ sample after irradiation to $0.1 \mathrm{dpa}$ at $350{ }^{\circ} \mathrm{C}$ with image locations noted. b) Confocal laser height map of the interface between the non-irradiated and irradiated regions. (c) Typical plot showing correlation between $\mathrm{H}^{+}$SRIM damage profile and sample height, measured using a confocal laser. Surface SEM micrographs of (d) non-irradiated, and (e) irradiated region of $\mathrm{Ti}_{3} \mathrm{AlC}_{2}$ sample which exfoliated during irradiation at $350{ }^{\circ} \mathrm{C}$. The black arrow in (d) indicates pores in the sample, the white arrow indicates the smaller darker grains which correspond to $\mathrm{TiC}$ impurities. Inset in (e) demonstrates the typical MAX phase layered structure. 
The results presented here provide further evidence that the damage tolerance of the MAX phases is directly related to temperature. By extrapolating the linear trends observed here for the irradiation induced c-lattice parameter change with temperature (Fig. 2c and d), we can estimate the point at which minimal residual defects are present. These temperatures are estimated to be $\sim 685{ }^{\circ} \mathrm{C}$ and $\sim 1,050{ }^{\circ} \mathrm{C}$ for $\mathrm{Ti}_{3} \mathrm{SiC}_{2}$ and $\mathrm{Ti}_{3} \mathrm{AlC}_{2}$, respectively, at the $\mathrm{H}^{+}$damage rate of $5.4 \times 10^{-6} \mathrm{dpa} \mathrm{s}^{-1}$. Tallman et al. reported that negligible lattice parameter changes were observed in $\mathrm{Ti}_{3} \mathrm{SiC}_{2}$ and $\mathrm{Ti}_{3} \mathrm{AlC}_{2}$ after neutron irradiation to $\sim 1.59 \mathrm{dpa}\left(2.59 \times 10^{-8} \mathrm{dpa} \mathrm{s}^{-1}\right)$ at $\sim 735{ }^{\circ} \mathrm{C}$ [10]. Previous work also showed that $\mathrm{Ti}_{3} \mathrm{SiC}_{2}$ had negligible lattice strains after neutron irradiation to $\sim 0.1 \mathrm{dpa}$ at the lower temperature of $695^{\circ} \mathrm{C}$ [28]. In this case, the neutron flux was not provided, so the damage rate is estimated to be $\sim 3.54 \times 10^{-8} \mathrm{dpa} \mathrm{s}^{-1}$ by assuming the same flux reported in their more recent work [10]. Negligible lattice strain is observed at a neutron irradiation temperature of $\sim 630{ }^{\circ} \mathrm{C}$ with a damage rate between 4.5 and $6 \times 10^{-7} \mathrm{dpa} \mathrm{s}^{-1}$ [12]. These studies suggest that the minimum temperature required to anneal defects may be lower at reduced damage rates.

Based on a range of observations of MAX phase irradiations, it is postulated that the actual dose received is not the most influential factor on lattice parameter changes. The damage rate, or flux, and irradiation temperature are believed to have a greater effect on lattice changes. Understanding the lattice response of different MAX phases to irradiation at specific damage rates, could allow a prediction of failure to be calculated, enabling the operational temperature range of these materials to be defined. Further systematic irradiation studies are required where only a single variable, e.g. dose rate or dpa is altered, so that usable conditions for these materials can be predicted. The different annealing temperatures of the two compositions suggests that modelling of defect stabilities for new MAX phase compositions may allow for identification of compositions which are able to operate at LWR temperatures. An example would be identifying compositions that don't promote interstitial carbon $\left(\mathrm{C}_{\mathrm{i}}\right)$ residing between A and $M$ layers.

In conclusion, the response of the MAX phases, $\mathrm{Ti}_{3} \mathrm{SiC}_{2}$ and $\mathrm{Ti}_{3} \mathrm{AlC}_{2}$ to high rates of proton induced damage, at varying irradiation temperatures, has been investigated. The rate at which recovery of the lattice parameters occurs is observed to be linear with temperature, where increasing irradiation temperatures, results in a reduction in lattice changes. The large changes observed in lattice parameters indicates clearly the limited irradiation tolerance of these materials at low temperatures. Furthermore, $\mathrm{Ti}_{3} \mathrm{AlC}_{2}$ is significantly less damage tolerant in the case of irradiation-induced proton damage compared with $\mathrm{Ti}_{3} \mathrm{SiC}_{2}$; its poor performance extending to significantly higher temperatures. When irradiated at $350{ }^{\circ} \mathrm{C}$, exfoliation of the 
irradiated surface of a $\mathrm{Ti}_{3} \mathrm{AlC}_{2}$ sample occurred at the relatively low damage level of $0.73 \mathrm{dpa}$, leading to the conclusion that in addition to the overall damage, it is also important to consider the damage rate when understanding the response of the MAX phase lattice to irradiation.

\section{Acknowledgements}

The authors wish to acknowledge the members of the Carbides for Future Fission Environments (CaFFE) programme for ongoing input and research collaboration.

\section{Funding}

Funding was provided by the Engineering and Physical Sciences Research Council (EPSRC) (EP/J021172/1, EP/I005420/1, EP/M018482/1 and EP/M018563/1) with additional funding provided by Rolls-Royce plc.

\section{References}

[1] M.W. Barsoum, M. Radovic, Mechanical Properties of the MAX Phases, Elsevier, 2004.

[2] M.W. Barsoum, T. El-Raghy, Journal of the American Ceramic Society 79 (1996) 1953-1956.

[3] B. Garcia-Diaz, L. Olson, C. Verst, R. Sindelar, E. Hoffman, B. Hauch, B. Maier, K. Sridharan, Transactions of the American Nuclear Society 110 (2014) 994-996.

[4] E.N. Hoffman, D.W. Vinson, R.L. Sindelar, D.J. Tallman, G. Kohse, M.W. Barsoum, Nuclear Engineering and Design 244 (2012) 17-24.

[5] D.W. Clark, S.J. Zinkle, M.K. Patel, C.M. Parish, Acta Materialia 105 (2016) 130146.

[6] M.K. Patel, D.J. Tallman, J.A. Valdez, J. Aguiar, O. Anderoglu, M. Tang, J. Griggs, E. Fu, Y. Wang, M.W. Barsoum, Scripta Materialia 77 (2014) 1-4.

[7] J.C. Nappé, I. Monnet, P. Grosseau, F. Audubert, B. Guilhot, M. Beauvy, M. Benabdesselam, L. Thomé, Journal of Nuclear Materials 409 (2011) 53-61.

[8] S. Liu, C. Wang, T. Yang, Y. Fang, Q. Huang, Y. Wang, Nuclear Instruments and Methods in Physics Research Section B: Beam Interactions with Materials and Atoms 406 (2017) 662-669.

[9] X. Liu, Le Flem Marion, J.-L. Béchade, F. Onimus, T. Cozzika, I. Monnet, Nuclear Inst. and Methods in Physics Research, B 268 (2010) 506-512.

[10] D.J. Tallman, L. He, J. Gan, E.N. Caspi, E.N. Hoffman, M.W. Barsoum, Journal of Nuclear Materials 484 (2017) 120-134.

[11] D.J. Tallman, L. He, B.L. Garcia-Diaz, E.N. Hoffman, G. Kohse, R.L. Sindelar, M.W. Barsoum, Journal of Nuclear Materials 468 (2016) 194-206.

[12] C. Ang, S. Zinkle, C. Shih, C. Silva, N. Cetiner, Y. Katoh, Journal of Nuclear Materials 483 (2017) 44-53.

[13] J. Ward, S. Middleburgh, M. Topping, A. Garner, D. Stewart, M.W. Barsoum, M. Preuss, P. Frankel, Journal of Nuclear Materials 502 (2018) 220-227. 
[14] G.W. Bentzel, M. Ghidiu, B. Anasori, M.W. Barsoum, Journal of the European Ceramic Society 35 (2015) 4107-4114.

[15] P.T. Wady, A. Draude, S.M. Shubeita, A.D. Smith, N. Mason, S.M. Pimblott, E. Jimenez-Melero, Nuclear Inst. and Methods in Physics Research, A 806 (2016) 109_ 116.

[16] R.E. Stoller, M.B. Toloczko, G.S. Was, A.G. Certain, S. Dwaraknath, F.A. Garner, Nuclear Instruments and Methods in Physics Research Section B: Beam Interactions with Materials and Atoms 310 (2013) 75-80.

[17] A.A. Coelho, J. Evans, I. Evans, A. Kern, Powder Diffraction 26 (2011) S22-S25.

[18] A. Kushima, X. Qian, P. Zhao, S. Zhang, J. Li, Nano Lett. 15 (2015) 1302-1308.

[19] J. Gruber, A.C. Lang, J. Griggs, M.L. Taheri, G.J. Tucker, M.W. Barsoum, Scientific Reports 6 (2016) 1-8.

[20] T. Ungár, Scripta Materialia 51 (2004) 777-781.

[21] J. Gubicza, X-Ray Line Profile Analysis in Materials Science, IGI Global, 2014.

[22] Le Flem Marion, X. Liu, S. Doriot, T. Cozzika, I. Monnet, International Journal of Applied Ceramic Technology 7 (2010) 766-775.

[23] S.W. Bedell, W.A. Lanford, Journal of Applied Physics 90 (2001) 1138-1146.

[24] S.J. Zinkle, Nuclear Instruments and Methods in Physics Research Section B: Beam Interactions with Materials and Atoms 286 (2012) 4-19.

[25] J.B. Condon, T. Schober, Journal of Nuclear Materials 207 (1993) 1-24.

[26] R.A. Langley, J. Bohdansky, W. Eckstein, P. Mioduszewski, J. Roth, E. Taglauer, E.W. Thomas, H. Verbeek, K.L. Wilson, Nucl. Fusion 24 (1984) S9-S117.

[27] E. Ligeon, A. Guivarc'h, Radiation Effects 27 (1976) 129-137.

[28] D.J. Tallman, E.N. Hoffman, E.N. Caspi, B.L. Garcia-Diaz, G. Kohse, R.L. Sindelar, M.W. Barsoum, Acta Materialia 85 (2015) 132-143. 